\title{
O horário eleitoral gratuito na televisão e o padrão das coligações em eleições majoritárias municipais
}

Humberto Dantas ${ }^{* *}$

\begin{abstract}
Resumo
O Horário Eleitoral Gratuito é uma forma de financiamento de campanhas que, segundo a Ciência Política, tem peso significativo no estabelecimento das estratégias dos partidos políticos. Assim, com vistas a aumentar seus respectivos tempos de exposição no rádio e na televisão, os partidos se coligam.

O argumento é bastante verificável nos planos estaduais e federal. Mas e nos municípios? Em cidades com retransmissora das três maiores empresas de TV do Brasil - Globo, Record e SBT - os partidos se comportam de forma diferente no que diz respeito à presença local, lançamento de candidatos e estabelecimento de alianças eleitorais? O presente artigo parte da hipótese central de que sim, existem diferenças estratégicas que diferenciam as 163 cidades onde as antenas das principais emissoras estão instaladas das demais.
\end{abstract}

\section{Introdução}

Em meio aos atuais debates sobre a forma mais adequada de financiamento de campanhas eleitorais no Brasil, em 2010 estima-se que o Horário Eleitoral Gratuito (HEG) custou aos cofres públicos, sob a forma de isenção de imposto de renda às emissoras de rádio e televisão, cerca de $\mathrm{R} \$ 850$ milhões (Câmara dos Deputados, 2010). Em 2008, ano de eleições municipais, o portal Carta Maior (2008) divulgou estimativa de isenção na ordem de pouco menos de $R \$ 243$ milhões às emissoras.

Importante salientar que desde 1974 a propaganda paga, por candidatos ou partidos, foi proibida no país. Até meados da década de 80 a veiculação do HEG era compreendida como uma obrigação das emissoras - concessionárias de um serviço público que, por explorá-lo, ficavam sujeitas às demandas compulsórias do Estado. A primeira previsão de ressarcimento surgiu com vistas às eleições de 1986 , por meio da

\footnotetext{
Esse artigo tem sido pensado desde as eleições de 2004. Parte expressiva dos argumentos e inquietações científicas foram divididos com outros cientistas políticos, aos quais registro meus devidos agradecimentos. A primeira versão desse trabalho foi apresentada na 35ㅇ Encontro Anual da ANPOCS, em 2011. Agradeço a todos que participaram do debate e deram suas contribuições.

*** Humberto Dantas é Doutor em Ciência Política pela USP e Professor e Pesquisador do Insper.
} 
lei 7.508 que regulava a propaganda eleitoral. Apesar do veto à destinação de recursos, o pagamento foi assegurado por meio de regulamentos eleitorais, ou seja: por decisões do Tribunal Superior Eleitoral e por meio do Decreto 93.253 de 12 de setembro de 1986, sancionado pela Presidência da República, interinamente nas mãos de José Fragelli ${ }^{1}$. Em 1997, com a Lei Eleitoral, a isenção foi legal e definitivamente assegurada.

A despeito da existência de estudos aprofundados, sobretudo no nível municipal, sobre a temática, a Ciência Política brasileira aceita com relativa facilidade a máxima de que, em eleições majoritárias, os partidos estabelecem coligações com o intuito de somar tempo ao HEG no rádio e na televisão (Lavareda, 1991; Nicolau, 1996; Fleischer, 2002 entre outros). Nos períodos que antecedem as disputas não é incomum o noticiário mostrar as negociações das principais legendas em torno desse relevante aspecto. Tal realidade é verificada nos pleitos federais (presidente) e estaduais (governadores) com significativa ênfase. Nas disputas majoritárias municipais (prefeitos) o fenômeno costuma ser mostrado com maior destaque nas capitais. Academicamente, como objeto de estudo, o HEG aparece centralmente sob o viés da influência que exerce sobre o eleitorado, ou ainda sob diferentes tentativas de análise acerca de estratégias de marketing político.

O objetivo principal desse artigo, no entanto, é compreender se a existência de emissoras de televisão em um dado município é capaz de alterar o padrão das coligações estabelecidas pelos partidos. Existem mais ou menos candidaturas? Mais ou menos partidos políticos presentes nessas cidades? As alianças são maiores, ou seja, concentram mais partidos? Em resumo: a TV altera o plano de aliança dos partidos?

As respostas aos questionamentos apresentados partem da hipótese central de que as coligações em cidades que possuem retransmissoras de televisão seguem um padrão diferente das demais localidades. Adicionalmente, e como resultado de tal

\footnotetext{
${ }^{1}$ Importante salientar que como presidente do Congresso Nacional de 1985 a 1987, Fragelli assumiu a Presidência da República por duas ocasiões curtas em setembro de 1986. Na primeira delas, de 9 a 14, assinou no dia 12 o decreto que determinava ressarcimento às emissoras de rádio e TV. O titular do cargo, José Sarney, presidente entre 1985 e 1990, e sua família (filhos), são sócios de emissoras de TV e rádio no Maranhão desde 1981 (rádio) e 1983 (TV). Uma das primeiras portarias que assinou como presidente, ainda no dia de sua posse em 15 de março de 1985, concedia quatro canais de TV no Maranhão. Em 1991, as emissoras do grupo deixaram de transmitir o sinal do SBT para se tornarem detentoras do direito de transmissão da Rede Globo.
} 
questão, espera-se pela existência de um número maior de candidatos nas cidades com TV, que graças ao alcance das antenas para outros municípios estabeleceriam estratégias de exposição visando ao aumento de chances em eleições estaduais, por exemplo - mesmo que tal argumento entre em conflito com tese de Duverger (1970) que aponta para o fato de que em eleições majoritárias de turno único existe tendência à bipolarização ${ }^{2}$. Além disso, parte-se do pressuposto da existência de uma quantidade maior de partidos nas cidades onde existe esse tipo de empresa de comunicação. Isso porque tal presença também poderia fazer parte de uma estratégia maior de aparição regional por parte das legendas. Assim, o intuito aqui está mais associado à compreensão dos debates sobre as coligações eleitorais do que propriamente ao debate corrente sobre o HEG enquanto ferramenta de comunicação partidária-eleitoral ou marketing político.

\section{Embasamento teórico}

Parece possível aceitar com bastante naturalidade que os partidos políticos se coligam com o objetivo de aumentarem suas respectivas chances de atingirem melhores resultados nas disputas eleitorais, argumento presente, por exemplo, em Figueiredo (1994). A ideia é reforçada por Kinzo (2004), para quem a análise do comportamento dos partidos brasileiros não pode desprezar a existência de alianças como peças fundamentais na formulação de estratégias.

Diversos trabalhos apontam as coligações como importante tema a ser estudado. As obras lançadas pela Fundação Konrad Adenauer e organizadas por Krause, Dantas e Miguel (2010) e Krause e Schmitt (2005) são bons exemplos de conjuntos de textos sobre o assunto. A despeito da existência de um grupo de pesquisadores preocupado com a questão, não são recentes os estudos acerca do fenômeno da associação eleitoral entre os partidos. Soares (1964), por exemplo, analisou as alianças no período 46-64 e concluiu que de posse das regras vigentes os partidos estabeleciam estratégias que tinham como intuito maximizar resultados, e tal gesto passava pelo estabelecimento de uniões para a disputa de votos.

\footnotetext{
${ }^{2}$ Destaque para o fato de que em 2008 apenas 1,4\% das cidades tinham possibilidade legal de realizar segundo turno em eleições para prefeito (majoritárias).
} 
Mais relacionado aos argumentos centrais desse artigo, Lavareda (1991) afirma que em coligações eleitorais até as pequenas legendas são bem-vindas junto aos maiores partidos, uma vez que lhes rendem recursos humanos, econômicos e minutos preciosos no HEG. Reforça o argumento a ideia de Nicolau (1996), que justifica as uniões entre partidos para a disputa de eleições por questões como: magnitude do distrito, tamanho do partido, tempo no horário eleitoral, poder de chantagem, número de candidatos que poderá lançar na chapa proporcional e a desigualdade da força dos partidos nos âmbitos estaduais.

Assim, se a coligação é peça chave na estratégia dos partidos, a soma de tempo no HEG justifica parte dessa opção. Os argumentos, entretanto, se concentram muito nos planos federal e estadual, ou seja, parte expressiva das análises sobre o peso da adição do tempo de HEG nas campanhas majoritárias não costuma levar em consideração as disputas municipais. É evidente que as justificativas poderiam servir para tais esferas de poder, mas parece razoável buscar compreender no âmbito local se existem diferenças expressivas entre os padrões de alianças em cidades com ou sem emissoras de TV.

\section{Escolhas analíticas e resultados}

Se o tempo no HEG faz parte das estratégias dos partidos no estabelecimento de suas coligações, é importante compreender o padrão desses acordos em cidades que possuem geradoras, comparando-as com aquelas que não dispõem. Para tanto, serão utilizados como base os dados do Tribunal Superior Eleitoral que conta com informações sobre 5.531 cidades, apesar de a eleição municipal de 2008 ter ocorrido em 5.564 municípios.

Com relação às emissoras, serão consideradas as cidades que possuíam retransmissoras das seguintes empresas: Globo, SBT e Record em 2007. Juntas, nesse ano, elas somavam $82,7 \%$ da audiência nacional e respondiam por $75 \%$ do total de geradoras das oito emissoras privadas de sinal aberto em operação no país (Grupo 
Mídia, 2007). Além disso, do total de 177 cidades $^{3}$ onde estão presentes as cinco principais emissoras de TV - Bandeirantes e Rede TV! completam a lista - em apenas 14 delas não existem as três empresas consideradas para o estudo. Nesse caso, os destaques em termos populacionais ficavam por conta de Uberaba (MG), Vila Velha (ES) e Pato Branco (PR) (idem).

Com base nas eleições em 5.531 cidades em 2008 e na lista de 163 locais onde estavam instaladas as três maiores emissoras em 2007, os dados foram analisados. Importante salientar, diante dessas escolhas, que o rádio também tem peso em termos do estabelecimento das estratégias dos partidos e disseminação do horário eleitoral. Em 2006 eram, ao todo, 3.766 emissoras distribuídas em todos os estados em um número significativamente maior de cidades (idem). A despeito dessa relevante informação, o estudo se concentrará na TV.

A Tabela 1 mostra a distribuição do total de retransmissoras por estado, além do total de municípios (com base nos dados do TSE), população e área estaduais. É possível notar que não existe um padrão claro associando proporcionalmente o total de cidades ao número de municípios com retransmissoras instaladas por estado, bem como não há como definir tal lógica utilizando a relação entre população e número de cidades com retransmissoras ou a área (em quilômetros quadrados) estadual. Há variações significativas nesses sentidos. No Ceará existe uma cidade com retransmissora para cada 181 municípios, enquanto essa relação cai para 5,6 no Mato Grosso. Em relação à população, os extremos se situam entre uma cidade com retransmissora para cada 121 mil habitantes no Mato Grosso e uma para cada 8,5 milhões no Ceará. Por fim, no que diz respeito à área do estado, o Rio de Janeiro tem uma cidade com retransmissora para cada 8,74 mil quilômetros quadrados enquanto essa relação sobe para 523,6 mil quilômetros no Amazonas. A despeito das distinções, o fato marcante é que todas as capitais possuem instalações das emissoras selecionadas.

\footnotetext{
${ }^{3}$ Brasília não está sendo considerada por não ter eleição municipal.
} 
Tabela 1 - Distribuição do total de retransmissoras por estado

\begin{tabular}{|c|c|c|c|c|c|c|c|}
\hline UF & $\begin{array}{r}\text { Cidades com } \\
\text { retransmiss. } \\
\text { (Grupo Mídia, } \\
\text { 2007) }\end{array}$ & $\begin{array}{r}\text { Total de } \\
\text { cidades na } \\
U^{4}\end{array}$ & $\begin{array}{r}\text { População } \\
\text { mil (IBGE- } \\
\text { 2010) }\end{array}$ & $\begin{array}{r}\text { Área mil } \\
\text { Km2 } \\
\text { (IBGE) }\end{array}$ & $\begin{array}{r}\text { Cidades } x \\
\text { retransmiss. }\end{array}$ & $\begin{array}{r}\text { População } \\
(\times 1000) \text { por } \\
\text { retransmissora }\end{array}$ & $\begin{array}{r}\mathrm{Km} 2(\times 1000) \\
\text { por } \\
\text { retransmissora }\end{array}$ \\
\hline$A C$ & 2 & 22 & 732,79 & 152,58 & 11 & 366,4 & 76,29 \\
\hline $\mathrm{AL}$ & 1 & 101 & $3.120,92$ & 27,77 & 101 & $3.120,92$ & 27,77 \\
\hline AM & 3 & 62 & $3.480,94$ & $1.570,75$ & 20,67 & $1.160,31$ & 523,58 \\
\hline AP & 1 & 16 & 668,69 & 142,81 & 16 & 668,69 & 142,81 \\
\hline BA & 6 & 409 & $14.021,43$ & 564,69 & 68,17 & $2.336,91$ & 94,12 \\
\hline CE & 1 & 181 & $8.448,06$ & 148,83 & 181 & $8.448,06$ & 148,83 \\
\hline ES & 4 & 78 & $3.512,67$ & 46,08 & 19,5 & 878,17 & 11,52 \\
\hline GO & 8 & 245 & $6.004,05$ & 340,09 & 30,63 & 750,51 & 42,51 \\
\hline MA & 9 & 214 & $6.569,68$ & 331,98 & 23,78 & 729,96 & 36,89 \\
\hline MG & 9 & 849 & $19.595,31$ & 586,53 & 94,33 & $2.177,26$ & 65,17 \\
\hline MS & 3 & 78 & $2.449,34$ & 357,12 & 26 & 816,45 & 119,04 \\
\hline MT & 25 & 140 & $3.033,99$ & 900,36 & 5,6 & 121,36 & 36,01 \\
\hline PA & 15 & 143 & $7.588,08$ & $1.247,69$ & 9,53 & 505,87 & 83,18 \\
\hline PB & 2 & 221 & $3.766,83$ & 56,44 & 110,5 & $1.883,42$ & 28,22 \\
\hline PE & 3 & 184 & $8.796,03$ & 98,31 & 61,33 & $2.932,01$ & 32,77 \\
\hline PI & 2 & 223 & $3.119,02$ & 251,53 & 111,5 & $1.559,51$ & 125,76 \\
\hline PR & 12 & 396 & $10.439,60$ & 199,31 & 33 & 869,97 & 16,61 \\
\hline RJ & 5 & 91 & $15.993,58$ & 43,7 & 18,2 & $3.198,72$ & 8,74 \\
\hline $\mathrm{RN}$ & 2 & 167 & $3.168,13$ & 52,8 & 83,5 & $1.584,07$ & 26,4 \\
\hline RO & 7 & 51 & $1.560,50$ & 237,58 & 7,29 & 222,93 & 33,94 \\
\hline $\mathrm{RR}$ & 1 & 15 & 451,23 & 224,3 & 15 & 451,23 & 224,3 \\
\hline RS & 13 & 496 & $10.695,53$ & 281,75 & 38,15 & 822,73 & 21,67 \\
\hline SC & 8 & 292 & $6.249,68$ & 95,35 & 36,5 & 781,21 & 11,92 \\
\hline SE & 1 & 75 & $2.068,03$ & 21,91 & 75 & $2.068,03$ & 21,91 \\
\hline SP & 16 & 643 & $41.252,16$ & 248,21 & 40,19 & $2.578,26$ & 15,51 \\
\hline TO & 4 & 139 & $1.383,45$ & 277,62 & 34,75 & 345,86 & 69,41 \\
\hline TOTAL & 163 & 5.531 & $190.755,00$ & $8.514,90$ & 33,93 & $1.170,28$ & 52,24 \\
\hline
\end{tabular}

Fontes: Grupo Mídia, 2007; IBGE, 2010e; Tribunal Superior Eleitoral (dados de 2008).

Diante do padrão heterogêneo da distribuição das antenas das três principais emissoras brasileiras pelo país, é necessário verificar o total de partidos políticos existentes nas cidades nas disputas de 2008 para que seja possível compreender a lógica das coligações. Das eleições municipais deste ano participaram formalmente 27 partidos. Por cidade, entretanto, de acordo com dados do Tribunal Superior Eleitoral a média de participação foi de 11,2 legendas, ou seja: a presença dessas organizações

\footnotetext{
${ }^{4} \mathrm{O}$ total não condiz com a somatória dos municípios brasileiros por falta de dados na base do TSE, ainda assim foram contempladas $99,3 \%$ das cidades.
} 
pelo país não é verificada de forma absoluta. Nos 163 municípios com emissoras de televisão essa média quase dobra, atingindo 20,1 partidos por cidade.

Importante salientar, entretanto, que de acordo com dados do Tribunal Superior Eleitoral existe aumento em proporção significativamente maior no contingente de eleitores por município: pouco mais de 23 mil eleitores no total de cidades contra pouco menos de 277 mil cidadãos nos municípios com emissora de televisão. Tal diferença é esperada em virtude das concessões e investimentos para instalação de transmissoras considerarem aspectos populacionais. Assim, à primeira vista, por mais que seja tentador associar os fatos, não parece possível afirmar que o número de partidos varie positivamente apenas, ou em grande medida, em virtude de as cidades possuírem retransmissoras de TV. Segundo Braga (2003), por exemplo, os partidos se organizam de forma mais clara em relação às orientações nacionais nas grandes cidades - algo bastante esperado de instituições que precisam somar votos. A questão, nesse caso, seria compreender o peso das realidades estaduais na organização dos partidos e o quanto as executivas nacionais conseguem de fato influenciar as decisões locais. Por sua vez, Dantas (2007) contraria o argumento de Braga apontando para uma descentralização do comportamento local dos partidos a despeito do tamanho das cidades, mostrando que, inclusive, os estatutos das legendas variam em relação ao peso do órgão federal nas decisões locais sobre as alianças eleitorais. Para buscar evidências mais consistentes em relação à questão da relação entre a presença das emissoras e o padrão das alianças eleitorais locais, uma solução é dividir os municípios de acordo com faixas populacionais segundo dados da Tabela 2.

Tabela 2 - Presença dos partidos em municípios com e sem TV

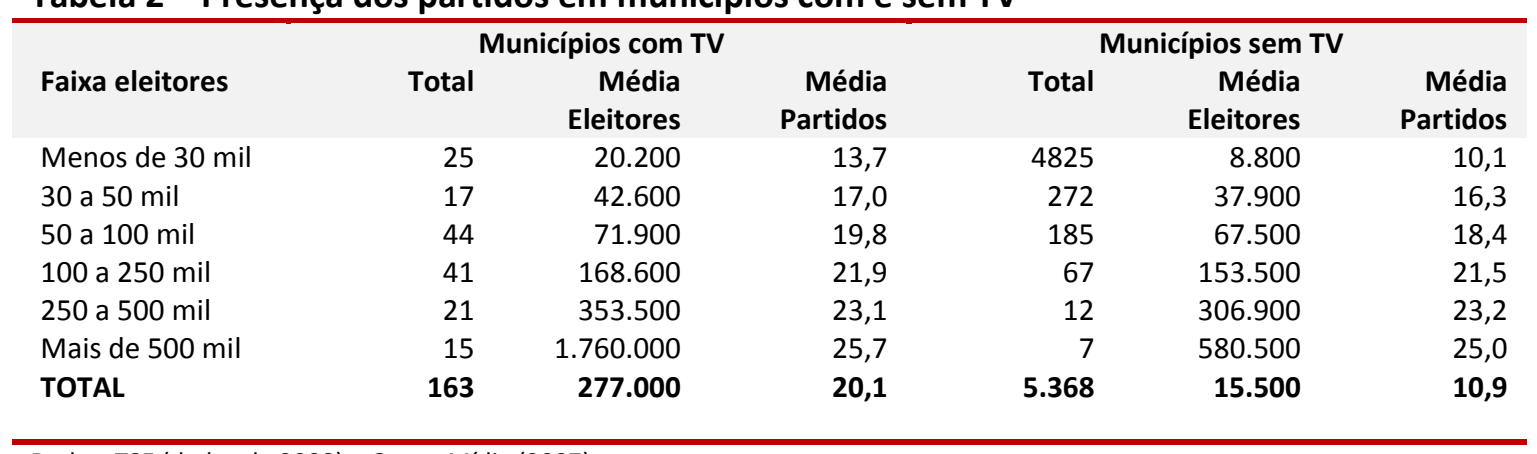

Dados: TSE (dados de 2008) e Grupo Mídia (2007) 
Nota-se que o peso significativo do volume de municípios com menos de 30 mil habitantes distorce interpretações acerca da variação de comportamento dos partidos nas cidades, bem como, por outro lado, a média da população de cidades com mais de 500 mil habitantes que possuem TV exerce a mesma influência sobre a análise dos grandes municípios. Assim, exceção feita às duas faixas extremas (menos de 30 mil habitantes e mais de 500 mil habitantes), é possível notar que não há variação significativa entre o número médio de legendas organizadas em um conjunto de cidades e a presença ou ausência de TV, ou pelo menos não parece possível afirmar que a existência ou não de TV exerça influência sobre a realidade. Tal fenômeno parece capaz de indicar que a hipótese central buscada neste artigo perde força.

A despeito de tal aspecto, chama atenção a citação encontrada em Dantas (2007) de um documento de 2004, lançado pelo então Partido da Frente Liberal (PFL) em Diário Oficial da União. Trata-se de parte das estratégias da legenda para os pleitos municipais daquele ano. Nele, ficava estabelecido que em municípios com mais de 50 mil habitantes, e naqueles com geradora de televisão, bem como nas capitais, a preferência do partido era pelo lançamento de candidatura própria. Uma estratégia mostrada assim, de forma tão clara, oferece a ideia de que o partido considera tal aspecto no lançamento de suas candidaturas - o que pode ser verdade, mas existe uma distância significativa entre as definições estratégicas de uma legenda e o que efetivamente seus diretórios locais colocam em prática - reforçando aqui a tese de Dantas (2007) e enfraquecendo as ideias de Braga (2003) apresentadas anteriormente.

Dantas (2007) e Dantas e Praça (2004) mostram que entre o discurso de órgãos nacionais dos partidos e o cumprimento de estratégias nos planos municipais existem diferenças, por vezes, abissais. No caso específico de Dantas e Praça (2004), por exemplo, o intuito foi mostrar que o posicionamento de lideranças estaduais e nacionais de partidos considerados nanicos a respeito de alianças em pleitos municipais não se converteu em ações efetivas nas disputas de 2000.

$\mathrm{O}$ caso do PFL não foi diferente. Ao se transformar em DEM e disputar as eleições de 2008, o partido lançou candidatos próprios em apenas 49 das 163 cidades que possuíam geradoras das principais emissoras do país, o que representa menos de 
um terço delas (30,1\%). É fato que entre $2004^{5}$ e 2008 a estratégia do partido pode ter sido alterada, e em sendo assim é possível afirmar que a atitude não se perpetua como plano ou não é seguida nos municípios. Em 2008, o partido que mais lançou candidaturas próprias nos municípios com TV foi o PT (92, ou 56,4\%), seguido pelo PMDB (89, ou 54,6\%), o PSOL (70, ou 42,9\%) e o PSDB (60, ou $36,8 \%$ ). A grande diferença, entretanto, está no total de cidades em que esses partidos lançaram candidatos: o PMDB lidera com 2.541, o PSDB tinha 1.702, o PT 1.611 e o PSOL 274. Se existe algum indício de estratégia associada à presença de televisão ela aparece de forma mais relevante no PSOL.

Se a hipótese acerca do interesse maior dos partidos políticos em cidades com retransmissora de TV não foi verificada, é importante analisar se o número de candidatos nessas cidades tem padrão diferenciado. Parte-se da ideia de que com espaço nos canais de comunicação os partidos teriam estímulos adicionais para firmarem seus principais nomes com vistas às eleições futuras, ou consolidação de sua marca na região para a qual a antena do canal transmite suas imagens. Contrária a essa hipótese, sobretudo nas cidades com menos de 200 mil eleitores, onde não há possibilidade de disputa de segundo turno, encontramos a já citada tese de Duverger (1970) para quem em eleições majoritárias de turno único há tendência à bipolarização ${ }^{6}$.

Existe, nesse caso, um primeiro indício de que a hipótese de alteração em virtude da televisão pode ser verdadeira. Enquanto nas cidades com retransmissoras são lançados em média 4,3 candidatos, nas demais o total cai para 2,6. O fato de haver o dobro de partidos nas cidades com televisão - 20 contra 11, conforme visto anteriormente - não deve servir de justificativa se a tese de Duverger estiver correta. Nesse caso, o que poderia variar de forma significativa é o total de partidos por coligação. A despeito de tal constatação preliminar a lógica de divisão das cidades de

\footnotetext{
${ }^{5}$ Em relação à estratégia traçada nesse ano, é importante salientar que o partido disputou apenas nove prefeituras de capitais com candidatos próprios, sendo que em seis encabeçou acordos e em três lançou-se sozinho. No total, conquistou apenas uma vitória, com César Maia no Rio de Janeiro. E disputou o segundo turno em Manaus, Fortaleza e Salvador, sendo derrotado em todos eles. Dos 150 maiores eleitorados municipais do país, o PFL conquistou apenas seis prefeituras.

${ }^{6}$ Dantas (2007) verifica que a tese de Duverger, nas eleições municipais brasileiras, tem força.
} 
acordo com faixas de habitantes pode trazer resultados mais consistentes para a análise.

Tabela 3 - Total de candidatos em municípios com e sem TV

\begin{tabular}{lcccccc}
\hline Faixa eleitores & Total & $\begin{array}{c}\text { Com TV } \\
\text { Média } \\
\text { Eleitores }\end{array}$ & $\begin{array}{c}\text { Média } \\
\text { Candidatos }\end{array}$ & Total & $\begin{array}{c}\text { Sem TV } \\
\text { Média } \\
\text { Eleitores }\end{array}$ & $\begin{array}{c}\text { Média } \\
\text { Candidatos }\end{array}$ \\
Menos de 30 mil & 25 & 20.200 & 2,8 & 4825 & 8.800 & 2,5 \\
30 a 50 mil & 17 & 42.600 & 3,1 & 272 & 37.900 & 3,2 \\
50 a $100 \mathrm{mil}$ & 44 & 71.900 & 3,4 & 185 & 67.500 & 3,4 \\
100 a $250 \mathrm{mil}$ & 41 & 168.600 & 4,8 & 67 & 153.500 & 4,0 \\
250 a $500 \mathrm{mil}$ & 21 & 353.500 & 5,5 & 12 & 306.900 & 4,9 \\
Mais de $500 \mathrm{mil}$ & 15 & 1.760 .000 & 7,7 & 7 & 580.500 & 5,4 \\
$\quad$ TOTAL & $\mathbf{1 6 3}$ & $\mathbf{2 7 7 . 0 0 0}$ & $\mathbf{4 , 6}$ & $\mathbf{5 . 3 6 8}$ & $\mathbf{1 5 . 5 0 0}$ & $\mathbf{2 , 6}$ \\
\hline
\end{tabular}

Dados: TSE e Grupo Mídia (2007)

No caso da Tabela 3 é possível verificar que em cidades maiores existe diferença no total de candidatos. Não se trata de algo tão expressivo se retirarmos da comparação as cidades com mais de 500 mil eleitores, onde a média de votantes em locais onde existe retransmissoras de TV é mais de três vezes superior àquela registrada nos municípios que não contam com esse tipo de empresa. Ainda assim, em cidades entre 100 mil e 250 mil eleitores a média de candidatos onde há antena é cerca de $20 \%$ superior e a média populacional $10 \%$ superior. Nesse caso, para verificar a tese de Duverger, torna-se necessário isolar as cidades em que existe a possibilidade legal de realização de segundo turno.

Em 2008 esse grupo de municípios com possibilidade de realização de segundo turno estava representado por 80 municípios, dos quais 48 continham as empresas de televisão selecionadas e outros 32 não as possuíam. Em ambos os subgrupos os partidos políticos estão significativamente presentes: 23,5 legendas por cidade. Esse empate permite uma visão mais acurada sobre o total de candidatos: 4,7 no caso das cidades sem televisão e 6,2 onde existem as emissoras consideradas, ou seja, no segundo caso temos 32\% mais concorrentes. Essa diferença é expressivamente menor que a distância de $123 \%$ associada à média da população desses subgrupos - 760 mil em cidades com TV contra 340 mil em cidades que podiam ter segundo turno em 2008 e não possuíam emissoras. Assim, não parece possível afirmar que a televisão seja o único fator, ou pelo menos um fator de notável relevância, nas estratégias das legendas em eleições municipais de uma maneira geral. É natural que tal variável faça 
parte dos acordos estabelecidos entre os partidos, mas o padrão de comportamento dessas organizações não se faz significativamente diferente quando utilizamos as emissoras para explicar suas posições em coligações face os argumentos lançados nesse estudo. Assim, a hipótese central desse trabalho parece capaz de ser refutada pela análise dos dados apresentados. Restaria, entretanto, verificar se o padrão ideológico das coligações é capaz de ser alterado.

\section{Conclusão}

As investigações desse estudo são preliminares, não atingindo expressivo grau de profundidade, mas buscando verificar aspectos associados à relação entre os padrões das coligações em disputas majoritárias municipais e a presença das emissoras de televisão nas cidades. Trata-se de uma tentativa de compreender o impacto de um relevante meio de financiamento público de campanhas nos padrões locais de aliança dos partidos.

Diante dos resultados apontados é possível afirmar que, inicialmente, a presença da TV não se configura em fenômeno capaz de alterar a forma de ação dos partidos de maneira relevante e generalizada. Não há como, entretanto, deixar de observar que tal variável é parte de um conjunto de aspectos a serem considerados pelos partidos em suas ações e pela ciência política em suas análises. Para Fleischer (2002), a forma de disputa da eleição, o tamanho do eleitorado, a existência de horários reservados para campanhas em televisão e rádio entre outras questões têm impactos relevantes nas realidades das campanhas. A despeito dessa questão, Dantas (2007) mostra que localmente, por vezes, os partidos agem de forma pouco associada a estratégias nacionais estabelecidas para pleitos municipais, o que pode desarticular objetivos como aqueles descritos no documento de 2004 do PFL. Assim, a falta de um padrão uniforme de ação por parte das legendas pode ser um fator determinante para explicar os resultados colhidos nesse estudo.

Outra limitação relevante da análise diz respeito à necessidade de um estudo mais acurado na distribuição das imagens dessas retransmissoras nas suas regiões e os resultados verificados nas eleições. Isso porque em muitas cidades os espectadores 
captam sinais em sistemas nacionais de comunicação - TV a cabo, via satélite ou sinal de parabólica. Nesse sentido, parte do que é gerado localmente pode não atingir o público alvo, restando saber como efetivamente funciona a distribuição de imagem para a compreensão acerca do impacto do horário eleitoral e consequente interesse dos partidos políticos por uma determinada localidade.

Outro dado relevante a ser investigado com o objetivo de apurar essa análise é o total de cidades com televisão que efetivamente fizeram uso desse instrumento. É sabido, no meio político, que em determinadas localidades partidos adversários chegam a assinar acordos para abrir mão de meios de comunicação como rádio e TV em virtude dos altos valores necessários para a produção de programas dessa natureza ${ }^{7}$.

Por fim, poderia ser interessante a realização de um estudo mais acurado sobre o padrão ideológico das coligações celebradas em cidades onde existe televisão. Preliminarmente, entretanto, é possível verificar, segundo o cruzamento dos dados do Tribunal Superior Eleitoral e o Anuário de Mídia (2007), que nas 163 cidades selecionadas para essa análise foram lançados 697 candidatos, dentre os quais 380 por coligações envolvendo dois ou mais partidos considerados grandes ${ }^{8}$. Coligações entre esquerda e direita foram estabelecidas em 76 chapas, ou seja, $20 \%$ das candidaturas envolvendo os grandes partidos. No total de cidades foram 10.852 candidaturas envolvendo duas ou mais dessas dez legendas e 1.698 mesclando legendas posicionadas em pontos opostos do espectro ideológico, representando $15,6 \%$ do total. Se considerarmos que as cidades com TV têm em média um número maior de eleitores e de partidos, essa diferença não parece capaz de tornar possível a afirmação associada ao fato de que as legendas cuidam do caráter ideológico em eleições onde existe a presença da TV na propaganda eleitoral.

Assim, com base nas análises realizadas com dados das eleições de 2008 não parece possível aceitar a hipótese central destacada no início desse artigo que tinha

\footnotetext{
${ }^{7}$ Em 2008, por exemplo, na cidade de Pradópolis-SP os três candidatos a prefeito acordaram que não utilizariam o rádio.

${ }^{8}$ Dantas (2007) trabalha com os dez maiores partidos brasileiros (ver classificação em seu trabalho) e utiliza classificação bastante aceita na Ciência Política brasileira: à esquerda PT, PSB, PDT e PPS; no centro PMDB e PSDB; e à direita PR, DEM, PP e PTB.
} 
como objetivo perceber um padrão diferenciado no comportamento dos partidos políticos em suas coligações em cidades onde existem retransmissoras dos três principais canais de televisão do Brasil. Quando divididas em faixas populacionais, exceção feita aos extremos das tabelas, as cidades com emissora de TV não possuem comportamentos diferentes do padrão verificado entre as localidades que não possuem tais empresas. Para compreender melhor a lógica das coligações foram verificados os totais de candidatos a prefeito, o total de partidos por cidade e a média de partidos por aliança. Todas essas características guardam relação direta com o estudo das coligações e poderiam ser determinantes para a compreensão da hipótese apresentada. A despeito do caráter simples dos métodos estatísticos utilizados, não parece ser possível afirmar que a sofisticação matemática seja capaz de trazer ao debate algo muito diferente de um afastamento em relação ao que se pretendia comprovar no início desse trabalho.

\section{Referências bibliográficas}

Braga, Maria do Socorro. 2003. O processo partidário eleitoral brasileiro: padrões de competição política (1982-2002). São Paulo, Tese de doutorado apresentada à DCP-USP.

Câmara Dos Deputados. 2010, Agência de Notícias. Horário eleitoral custa mais de R\$ 850 milhões ao contribuinte. 17-08-2010, acesso em 06 de outubro de 2011 às 11 h00. Endereço: http://www2.camara.gov.br/agencia/noticias/POLITICA/150080-HORARIO-ELEITORAL-CUSTAMAIS-DE-R\$-850-MILHOES-AO-CONTRIBUINTE.htmI

Carta Maior. 2008. Emissoras de rádio e TV ganham R\$ 242,3 nilhões com isenção. 01-092008, acesso em 06 de outubro de 2011 às 11h00. Endereço: http://www.cartamaior.com.br/templates/materiaMostrar.cfm?materia id=15210.

Dantas, Humberto. 2007. Coligações em eleições majoritárias municipais: a lógica do alinhamento dos partidos políticos brasileiros nas disputas de 2000 e 2004. São Paulo, tese de doutorado apresentada ao Departamento de Ciência Política da USP.

Dantas, Humberto e Praça, Sérgio. 2004. "Os pequenos partidos nas coligações eleitorais para prefeituras em 2000". Revista Leviatã, n. 1. São Paulo, Hucitec DCP-USP.

Duverger, Maurice. 1970. Os partidos políticos. Zahar Editores, Rio de Janeiro.

Figueiredo, Marcus. 1994. "A lei de ferro da competição eleitoral: a aritmética eleitoral". Cadernos de Conjuntura, Rio de Janeiro, IUPERJ, n. 50, jul. 
Fleischer, David. 2002. "As eleições municipais no Brasil: uma análise comparativa (19822000)". Opinião Pública, v 8, n 1, Campinas.

Grupo Mídia. 2007. Anuário de Mídia. São Paulo: Grupo Mídia.

Kinzo, Maria. D’Alva Gil. 2004. "Partidos, eleições e democracia no Brasil pós-85", Revista Brasileira de Ciências Sociais, vol. 19, 54, São Paulo, fevereiro.

Krause Silvana, Schmitt Rogério (orgs). 2005. Partidos e coligações eleitorais no Brasil. Rio de Janeiro: Fund. Konrad Adenauer; São Paulo: UNESP.

Krause, Silvana. Dantas, Humberto. e Miguel, Luis Felipe. (orgs). 2010. Coligações partidárias na nova democracia brasileira. Rio de Janeiro: Fundação Konrad Adenauer.

Lavareda, Antônio. 1991. A Democracia nas Urnas: O Processo Partidário Eleitoral Brasileiro. Rio de Janeiro, Rio Fundo/luperj.

Nicolau, Jairo. 1996. Multipartidarismo e democracia. Rio de Janeiro, Ed. FGV.

Soares, Gláucio. 1964. Alianças e coligações eleitorais: notas para uma teoria. Revista Brasileira de Estudos Políticos, n. 17, julho. 